\title{
Gastrectomía total oncológica laparoscópica
}

Laparoscopic total oncologic gastrectomy

Pablo Valsangiacomo ${ }^{1}$

ORCID https://orcid.org/0000-0003-2028-5552

Maite Campos ${ }^{2}$

ORCID https://orcid.org/0000-0002-2821-7012

Mauro Perdomo ${ }^{3}$

ORCID https://orcid.org/0000-0001-6470-6107

Martín Bentancur ${ }^{4}$

ORCID https://orcid.org/0000-0003-4816-2095

Daniel González González ${ }^{5}$

ORCID https://orcid.org/0000-0003-3916-9201

DOI: $10.31837 /$ cir.urug/5.1.5

Recibido: $\quad 17$ de enero de 2020

Aceptado: $\quad 07$ de julio de 2020

\section{Introducción}

La gastrectomía oncológica laparoscópica ha aumentado en los últimos años debido a los beneficios postoperatorios, manteniendo los principios oncológicos.

Describimos los principales aspectos técnicos de la gastrectomía total oncológica laparoscópica.

\section{Descripción de contenidos}

Paciente portador de un adenocarcinoma gástrico avanzado subcardial.

Comenzamos con lavado peritoneal, apertura del

GASTRECTOMIATOTAL ONCOLOGICA LAPAROSCOPICA

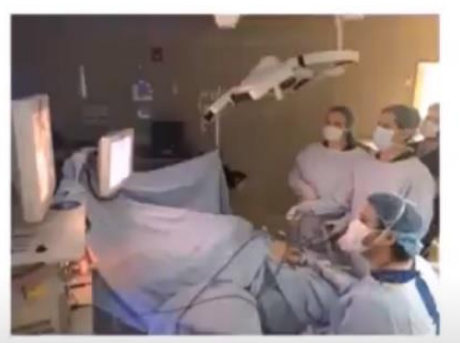

Dres. Valsangiácomo P, Campos M, Perdomo M, Bentancur M., González D.

Clínica Quirúrgica 3. Hospital Maciel. Facultad de Medicina. Montevideo. Uruguay.

epiplón mayor, resecando los ganglios del grupo 4 y 5, sección del pedículo gastroepiploico derecho resecando el grupo 6. Sección del duodeno y linfadenectomía del grupo 8, 9 y 11.

Sección de la arteria coronaria estomáquica (grupo 7). Resección del epiplón menor hasta el hiato esofágico y resecamos los grupos ganglionares 1,2 y 3.

Seccionamos el esófago, extraemos la pieza y resección del epiplón mayor. Reconstrucción del tránsito digestivo en Y de Roux.

\section{Conclusiones}

La gastrectomía laparoscópica oncológica es una técnica factible y segura. Su realización requiere experiencia en cirugía oncológica esofagogastrica y en cirugía laparoscópica de avanzada. 
$\overline{\text { 1,2,3,4,5 Clínica Quirúrgica 3. Hospital Maciel. Facultad de Medicina, Universidad de la República, Montevideo, Uruguay }}$ pvalsangiacomo@gmail.com 